\title{
Rio de Janeiro: imagens da cidade
}

MOACYR FLORES*

Resumo: O presente artigo analisa as imagens da cidade do Rio de Janeiro, nos séculos XIX e XX, criadas e interpretadas por dramaturgia simbólica.

Abstract: The present article analyses the images city of Rio de Janeiro in the nineteenth e twentieth centuries, creates and interprets by symbolic dramaturgy.

Palavras-chave: Imagem. Memória. Urbanização.

Key words: Image. Memory. Urbanization.

Kevin Lych afirma que o cenário urbano só se torna compreensível quando se conhece o modo como os habitantes percebem sua cidade através de indicadores como sensações visuais, forma, cores, movimento e polarização da luz (Lynch, 1997, p. 11).

Como estabelecer a imagem da cidade, formada pelas sensações visuais do observador, com seus significados práticos ou emocionais? Creio que um dos caminhos é procurar identificar a origem da formação da imagem urbana por seus moradores e pessoas em trânsito. A imagem é construída de diversas maneiras, uma delas é o uso de reminiscências ou símbolos coletivos pela comédia de costumes, um dos gêneros do teatro brasileiro, que critica ou satiriza usos e costumes de uma determinada cidade e época, bem como reproduz no palco as articulações entre lugares marcantes, caracterizando as formas urbanas e o relacionamento das pessoas.

José de Alencar e Arthur de Azevedo, dois dramaturgos que marcaram o teatro nacional, usaram o ambiente da cidade do Rio de Janeiro como local de ação da comédia "Rio de Janeiro, verso e reverso" e da burleta "A Capital Federal", o primeiro no período do Império e o segundo, no início da República.

* Professor do Departamento de História e do Programa de Pós-Graduação em História da PUCRS.

Estudos Ibero-Americanos. PUCRS, v. XXX, n. 2, p. 121-130, dezembro 2004 
Os dois dramaturgos estruturam imagens urbanas que se cruzam e se completam em cores fortes dos tipos humanos característicos, em sensações que estabelecem o reconhecimento de símbolos locais. Há também comparações do ambiente de cidades do interior com a capital do Brasil, através dos cenários e diálogos dos personagens. Tanto a imagem individual do autor teatral, como a coletiva dos espectadores são elaboradas através de símbolos marcantes da cidade, como a Rua do Ouvidor, Laranjeiras, Grande Hotel, Largo da Carioca, Arcos da Santa Teresa ou o Belódromo Nacional, pontos referenciais da memória da cidade. Essa memória elaborada contém uma crítica humorística aos usos e costumes do Rio de Janeiro, cidade modelo para as cidades provincianas que imitavam a moda, a maneira de ser e até no modo de falar. Assim, a Rua do Ouvidor é colocada no palco como um marco da cidade progressista com suas lojas e movimento de pedestres. O Largo da Carioca é outro local de encontro e de relacionamento de pessoas dos mais diferentes tipos, que esperam pelo bonde elétrico, símbolo marcante do progresso urbano.

\section{Rio de Janeiro: verso e reverso}

O primeiro ato da comédia Rio de Janeiro, verso e reverso, levada à cena em 28 de outubro de 1857, de autoria de José de Alencar (1829-1877), apresenta a imagem humorística da famosa Rua do Ouvidor, tendo como figurantes, os vendedores de bilhetes de loteria, passadores de ingressos para festas artísticas, vendedores de fósforo, poeta coletando dinheiro para futura publicação de livro, formando uma coleção de tipos pitorescos que se movimentam pelo ambiente urbano. A Rua do Ouvidor era um símbolo forte da capital do Império, devido à intensidade de sua vida e ao aglomerado de gente da sociedade carioca, era o local onde se depositavam as reminiscências coletivas da cidade.

A trama da comédia Rio de Janeiro, verso e reverso é simples e ingênua. Ernesto é um jovem do interior paulista que chega à cidade do Rio do Janeiro, a qual ele considera um pandemônio com seus vendedores ambulantes, onde tudo e até as mulheres são artificiais. Júlia pergunta ao primo Ernesto o que tem achado do Rio de Janeiro. A imagem que ele traça não é lisonjeira, é estruturada pela emoção provocada a um interiorano atordoado que chega a uma grande cidade: 
Ernesto. Eu lhe conto. Logo que cheguei, não vi, como já lhe disse, no aspecto geral da cidade, nada que me impressionasse. Muita casa, muita gente, muita lama; eis o que há de notável. Porém isto não é nada; de perto é mil vezes pior.

Júlia. E depois? Quando passeou?

Ernesto. Quando passeei? Por ventura passeia-se no Rio de Janeiro? O que chama a senhora de passear? E andar um homem saltando na lama, como um passarinho, atropelado por uma infinidade de carros, e acotovelado por todo mundo? É não ter um momento de sossego, e estar obrigado a resguardar os pés de uma carroça, o chapéu de um guarda-chuva, a camisa dos respingos de lama, e o ombro dos empurrões? Se é isto que a senhora chama passear, antão sim, admite que se passeie no Rio de Janeiro; mas é preciso confessar que não são muito agradáveis esses passeios (Alencar, 1977, ํํv, p 18).

Ernesto é convidado para passar uns dias na casa da prima, no bairro Laranjeiras, ele recusa porque lá os passeios se transformam em banho de poeira e de suor. Também não quer saber de bailes que são divertimentos apenas para modistas e confeiteiros. Critica as moças cariocas por causa das roupas e chapéus da moda:

Ernesto. No Rio de Janeiro, prima há balões, crinolinas, chapéus à pastora, bonecas cheias de arames, tudo o que a Sra. quiser; porém moças, não; não posso admitir. Ignoro que haja no mundo uma degeneração da raça humana que tenha a cabeça mais larga do que os ombros; que carregue uma concha enorme como certos caramujos, que apresente enfim a forma de um cinco (Alencar, 1977, 2ำ v., p. 20).

Ele explica que o corpo das moças é uma haste fina, o balão do vestido forma a volta do número, e o chapéu arrebitado é o traço acima. Essa crítica atinge em cheio o traje da prima Júlia, vestida à moda da época.

Depois de três meses o provinciano Ernesto passa a viver como os demais habitantes da cidade grande, inclusive comprando a crédito e se endividando. Ernesto também muda a imagem que tem da cidade, até a confusão nas ruas tira a monotonia do passeio, até os peditórios estão dentro da caridade evangélica e o passeio ao Corcovado permite uma visão da cidade que recebeu o nome de princesa do vale. Essa mudança se explica pelo amor que sente pela prima. José de Alencar dá um final feliz à comédia, Ernesto ganha a sorte grande num bilhete que comprou e assim, estando rico, pode pedir a mão da prima, pois pretende se estabelecer no Rio de Janeiro, numa casinha do arrabalde, ambiente longe do labirinto das ruas do centro da cidade. 
Ernesto, que ao chegar ao Rio de Janeiro não se adaptava à complexa ordem da metrópole por sua intensidade de vida e aglomerado de gente, mas depois de três meses, conseguindo identificar e estruturar a imagem urbana, considera a metrópole brasileira não mais aterradora, mas romântica e admirável, porque compreende os agrupamentos humanos, as associações e as interligações das atividades humanas, como vender bilhetes, fósforos, ações da Bolsa de Valores, esmola, namoro e casamento. Através dos olhos de Júlia, a mulher amada, Ernesto reformula a imagem urbana diante de novo olhar crítico.

\section{A Capital Federal}

A burleta ou comédia-opereta "Capital Federal", escrita em 1897, pelo comediógrafo Arthur Azevedo, é uma fonte da história social do Rio de Janeiro, na virada do século, quando surgem novos elementos de tecnologia transformando a cidade e atraindo pessoas de todos os lugares. É interessante destacar as mudanças de valores dos habitantes da cidade em relação aos moradores do interior, identificados como moradores de lugares onde o pregresso não chegou. Arthur Azevedo reuniu os personagens e figurantes no Grande Hotel, espaço onde todos se encontram como vítimas dos enganos da grande cidade e em locais organizados pela da imagem urbana criada por Arthur Azevedo, facilmente identificáveis pelos cenários e referências nas falas dos personagens.

Arthur Azevedo escreveu e encenou a comédia-opereta em três atos e 12 quadros, com música alegres e leves de Nicolino Milano, Assis Pacheco e Luiz Moreira, sem "contudo descer até o gênero conhecido pela característica denominação de maxixe", conforme explicação de Azevedo no Jornal A Notícia, de 4 de fevereiro de 1897, pois sua intenção era escrever uma peça espetaculosa e de fazer uma boa figura.

No primeiro quadro do primeiro ato, há uma confusão no vestíbulo do hotel, com reclamações dos hóspedes. O gerente caracteriza o Grande Hotel, comparando-o com os de São Paulo:

Gerente. Não há mãos a medir! Pudera! Se nunca houve no Rio de Janeiro um Hotel assim! Serviço elétrico de primeira ordem! Cozinha esplêndida, música de câmara durante as refeições da mesa redonda! Um relógio pneumático em cada aposento! Banhos frios e quentes, duchas, sala de natação, ginástica e massagem! Grande salão com um plafond pintado pelos nossos primeiros artistas! Enfim, uma verdadeira novidade! - Antes de nos estabelecermos aqui, era 
uma vergonha! Havia hotéis em São Paulo superiores aos melhores do Rio de Janeiro! Mas em boa hora foi organizada a Companhia do Grande Hotel da Capital Federal, que dotou esta cidade com melhoramento tão reclamado (Azevedo, 1965, p. 11).

O gerente do Hotel mostra a competição existente entre paulistas e cariocas para ver quem possui a cidade mais moderna. No final do século XIX a eletricidade era um sinal de modernidade tecnológica, não só para a iluminação como também para aquecer a água do banho. Havia um imaginário de que era possível conseguir a cura de diversas doenças por banhos quentes e frios, alternadamente. Era a época da descoberta do corpo, com a prática de esportes, natação, ginástica e massagem. O homem devia ter bíceps salientes e uma caixa torácica saliente. As mulheres começavam a trocar o espartilho pelo prático sutiã, fazer permanentes, usar tinturas nos cabelos e hidratar a pele com creme Nívea, que era apenas parafina perfumada. A prática de ginástica e esportes estava proibida para mulheres, pois elas deviam apresentar um aspecto frágil e meigo. Anunciando os melhoramentos do hotel, o gerente relaciona os elementos de progresso urbano do Rio de Janeiro.

Arthur Azevedo coloca em cena personagens que representam grupos sociais do Rio de Janeiro sob forma de estereótipos identificáveis. Assim apresenta-se Lola, mulher de vida fácil que se identifica como espanhola para melhor explorar a riqueza dos homens, fingindo por eles louca paixão. Outro tipo é o Gouveia, jogador inveterado que só apostas nas dúzias do jogo de corridas de bicicletas, nova paixão da cidade. Figueiredo é o típico carioca que só vive reclamando, mas tem predileção pelas mulatas desde que esteve na Bahia. Dedica-se a "lançar" as mulatas na prostituição. A esses tipos da cidade opõe-se a família de fazendeiros de São João do Sabará, com suas malas, trouxas e embrulhos, que se hospeda no hotel em busca de um janota da cidade que prometeu casamento para a inocente filha Quinota. Figueiredo, o lançador de mulatas, se impressiona pela criada Benvinda, tratando-a como objeto de desejo para um próximo "lançamento".

O segundo quadro da Capital Federal tem como cenário uma agência que indica onde há casas para alugar. Cobra cinco mil réis pela informação. A sala se enche de pessoas reclamando que as casas já estavam ocupadas e querem de volta o dinheiro que deram pela indicação. A ladroeira prossegue, o dono da agência indica sua própria casa para alugar: 
Proprietário. Um sobrado com três janelas de peitoril. Os baixos estão ocupados por um açougue.

Mota e Figueiredo. Xi!

Senhora. Deve haver muito mosquito.

Proprietário. Mosquitos há em toda a parte. Sala, três quartos, sala de jantar, despensa, cozinha, latrina na cozinha, água, gás, quintal, tanque de lavar e galinheiro.

Senhora. Não tem banheiro?

Proprietário. Terá se o inquilino o fizer. A casa foi pintada e forrada há dez anos; está muito suja. Aluguel, duzentos e cinqüenta mil réis por mês. Carta de fiança passada por negociante matriculado, trezentos mil réis de posse e contrato por três anos. O imposto predial e de pena d'água é pago pelo inquilino.

Senhora. Com os três mil réis que me surrupiou compre uma corda e enforque-se! (Azevedo, 1965, p. 37).

Os três querem surrar o proprietário da agência que foge. $\mathrm{Na}$ saída esbarram com a família mineira. O fazendeiro Euzébio pretende alugar o sobrado que tem na parte de baixo um açougue e fica numa praia, na periferia da cidade. Azevedo traça o cenário do arrabalde distante, com o mau cheiro do ambiente e com as nuvens de mosquitos.

O quadro III apresenta como cenário o Largo da Carioca, ponto nodal dos transportes precários da cidade. As pessoas esperam o bonde elétrico há mais de meia hora. As reclamações contra o serviço de bonde se sucedem:

Figueiredo. É tudo assim no Rio de Janeiro! Este serviço de bondes é terrivelmente malfeito!

Rodrigues. Que diabo! Não sejamos tão exigentes! Esta companhia não serve mal. Não é por culpa dela esse atraso. Ali na estação me disseram. Na rua do Passeio está uma fila de bondes parados diante de um enorme caminhão, que levava uma máquina descomunal não sei para onde, e quebrou as rodas. É ter um pouco de paciência (Azevedo, 1965, p. 47).

A Capital Federal, ainda com ruas estreitas e com calçamento antigo, não suportava o aumento do volume de veículos de transporte. Era a época do caminhão, maior e mais pesado, competindo com as carroças de carga puxadas por mulas. O Largo da Carioca por ter uma estação de bondes e também por ser o local onde passavam várias linhas de bondes, era um pólo de encontro de pessoa de diferentes categorias, trabalhadores como o Rodrigues, cafetões como o Figueiredo, jogadores como Gouveia, empregadas domésticas como a Benvinda e meretrizes como a Lola, Mercedes, Blanchette e Dolores, misturados com pessoas do povo. $\mathrm{O}$ cenário 
identifica o Largo da Carioca como um elemento reconhecível da cidade do Rio de Janeiro, por parte dos espectadores da platéia, que possivelmente passaram por situação semelhante à espera de bonde.

Para completar o quadro social do Largo da Carioca aparece o mineiro Eusébio com a mulher Fortunata, a filha Quinota e o filho Juquinha, todos a procura do Gouveia que havia prometido casamento para filha do rico fazendeiro, morador em São João do Sabará, cidade pequena e pacata do interior de Minas Gerais, que serve de comparação com a fervilhante Rio de Janeiro.

O quadro seguinte mostra a família mineira no bonde elétrico sobre os arcos de Santa Teresa, extasiada com o panorama da "capitá federá". Os Arcos de Santa Teresa, como um dos fragmentos urbanos, simbolizam a cidade e participam de seu cotidiano através da linha do bonde, facilmente identificáveis pelos espectadores do teatro. Os nomes das ruas e dos bairros identificam os locais da ação e da crítica ao ambiente, fortalecendo a construção da imagem da cidade.

Na Capital Federal há uma postura carioca, que contrasta com as pessoas interioranas. Figueiredo, o cafetão, prepara a mulata Benvinda para ser lançada no meretrício: ensina-a a caminhar olhando para um ponto fixo como os que andam na corda bamba, a rebolar os quadris com moderação e, principalmente, a falar pronunciando os erres finais e a sibilar os esses, ser elegante e usar uma boa prosódia. É de bom tom dizer uma palavra ou usar uma expressão francesa, que a pobre da mulata caipira não consegue pronunciar, diferente de Lola que se exprime com elegância e sabe como explorar os homens através de palavras e atos sensuais.

Outra imagem referencial das grandes cidades é a de ser um local de perdição. O comediógrafo Azevedo coloca em cena a saleta elegante de Lola, ambiente simbólico, onde ela e o cocheiro Lourenço enganam o fazendeiro Euzébio para lhe arrancar dinheiro e ao Duquinha, um jovem tímido que faz versos e traz flores, em lugar de jóias. Em poucos dias, o tolo do fazendeiro entregou cinco contos para a esperta mulher.

A imagem que Quinota, a filha do fazendeiro Eusébio, tem do Rio de Janeiro é de um lugar perigoso que perde as pessoas, como seu pai, homem da roça, e a criada Benvinda:

Quinota. Que vida tão diversa da vida da roça! (A Gouveia.) Não ficaremos aqui depois de casados.

Gouveia. Por que? 
Quinota. A vida fluminense é cheia de sobressaltos paras verdadeiras mães de família!

Fortunata. Olhe seu Eusébio, um homem de cinqüenta ano, que teve até agora tanto juízo! Arrespirou o á da capitá federá e perdeu a cabeça.

Quinota. Aqui há muita liberdade e pouco escrúpulo... faz-se ostentação do vício... não se respeita ninguém... é uma sociedade mal constituída (Azevedo, 1965, p. 162).

O Belódromo Nacional, local de corridas de bicicletas, com apostas no número de cada ciclista, é outro local de perdição. Arthur Azevedo coloca no palco as diferentes artimanhas dos apostadores para fazerem as combinações dos números das apostas. Lá também chega a mulata Benvinda que está cansada de ser corrigida na postura e na fala pelo cafetão Figueiredo, o lançador de mulatas. Ela rompe com Figueiredo e cai nas graças do cocheiro Lourenço, mas Benvinda o repele porque deseja sair da vida de meretriz e viver em família. Ele retruca que não é mais possível viver em família no Rio de Janeiro por causa do alto custo de vida:

Lourenço. Já não se encontra casa decente, que custe apenas uns cem mil réis e os senhorios constantemente o preço aumentam dos aluguéis. [...] Carne de vaca não come o pobre, e qualquer dia não come pão! Fósforos, velas, couve, quiabos, vinho, aguardente, milho feijão, frutas, conservas, cenouras nabos, tudo se vende por um dinheirão! (Azevedo, 1965, p. 151-152).

Juquinha, com o nome de Colibri, é um dos ciclistas que consegue vencer a corrida. Fortunata e Quinota, junto com Gouveia vão ao Belódromo onde todos se encontram, terminando a cena com correrias.

A burleta tem um final esperado: o velho Eusébio abandona a Lola, que é roubada pelo cocheiro Lourenço. Gouveia está sem dinheiro, perdeu tudo no jogo, mas segue o conselho de Quinota, conta tudo ao pai que retorna para os braços de sua velha mulher, restabelecendo a família tradicional da cidade interiorana.

Artur Azevedo escreveu sainetes (mini-dramas) no jornal O Século, de 1906-1908, com comentários ligeiros sobre acontecimentos urbanos: a reunião pan-americana, onde um comerciante português não sabem o significado da palavra, consultam o dicionário e encontram pan, deus grego que inventou a flauta, concluído que a reunião é pura flauteação.

No sainete Confraternização, o tema é a visita do presidente argentino, que resultou apenas em festas: 
Primeira Filha. Que pena ter-se ido embora o Roca! Acabaram-se as festas!

Segunda Filha. Papai foi muito bonzinho, pois nos levou a todas elas!

Jornalista. Menos ao baile das Relações Exteriores, porque seria preciso gastar uma fortuna só em toilettes, mas não creiam, meninas, que eu as levasse às festas só por divertimento.

Terceira Filha. Então por que foi, papai?

Jornalista. Levei-as às festas por ser bom brasileiro e querer que o meus país viva em boa harmonia com as nações limítrofes (Azevedo, 1977, p. 74-75).

No entanto, o Jornalista termina dizendo que no jornal escreve pela confraternização, mas em casa diz dos argentinos cobras e lagartos.

O plano de demolição das casas térreas para a construção de sobrados, a fim de embelezar a cidade do Rio de Janeiro, não escapou da crítica de Arthur Azevedo:

Mello. Pois gabo-lhe a pachorra. Depois que se meteu em cabeça a esses malucos embelezarem o Rio de Janeiro (como se o Rio de Janeiro não fosse uma tetéia!) não param os sustos.

Santos. Deixe lá! Não é tanto assim! Eles incomodaram os proprietários, mas valorizam a propriedade.

Mello. Pois, sim, mas olhe agora o projeto do tal Nery Pinheiro que quer acabar com as casas térreas!

Santos. Pois isso o prejudica?

Mello. Se me prejudica? Nada, uma brincadeira! Pois se eu não tenho senão casas térreas! (Azevedo, 1977, p. 90).

O protesto de Mello, proprietário de mais de 60 casas térreas, se justifica porque a prefeitura não arcaria com o ônus da demolição e da construção de novo prédio, cabendo esse ao proprietário.

A violência no Rio de Janeiro também está presente em seis sainetes que se referem ao crime da Rua da Carioca, que teve como vítima um joalheiro e o medo da população, à mercê dos bandidos. O Borba, um chefe de família, temendo mal maior, manda a mulher e filhas fecharem portas e janelas enquanto os ladrões roubam galinhas no pátio (Azevedo, 1977, p. 44-46).

Outras imagens passam pelos sainetes de Azevedo: crítica aos bondes; ao novo sistema de transporte; aos automóveis e ao balão a gás; à fundação da sociedade protetora de animais contra os maus tratos; ao recenseamento da população; à introdução da vacina contra a varíola; à falta de higiene nas fábricas de cerveja; à inauguração do novo mercado coberto na Praia de Dom Manoel que em breve estará sujo e mal cheiroso como o antigo. 
O teatro é um dos meios formadores da memória brasileira ao colocar em cena aspectos da vida doméstica, problemas urbanos, escândalos sociais, crimes famosos e flagrantes políticos, tecendo a rede de intrigas que se entrecruzam nas malhas de uma cidade. A comédia de costumes, como as de José de Alencar e Arthur Azevedo, dois notáveis comediógrafos do teatro nacional, dão testemunho de um passado, com fatos, instituições, figuras e costumes que nos permitem reconstituir as imagens em escala urbana que tinham nossos antepassados em determinada época, quando Rio de Janeiro, com suas mazelas, ainda não era chamada de "Cidade Maravilhosa".

\section{Referências}

ALENCAR, José de. Teatro completo. Rio de Janeiro: Serviço Nacional de Teatro, 1977. $2 \mathrm{v}$.

AZEVEDO, Arthur. A Capital Federal. Rio de Janeiro: Letras e Artes, 1965.

. Teatro a vapor. São Paulo: Cultrix/Brasília: INL, 1977.

LYNCH, Kervin. A imagem da cidade. São Paulo: Martins Fontes, 1997. 